\title{
Transnational education as an internationalisation strategy: Meeting the institutional management challenges
}

\section{Sally Stafford and John Taylor}

\begin{abstract}
The importance of transnational programmes as part of the internationalization of higher education has grown rapidly in importance in recent years. In this paper, transnational higher education is defined as the delivery of programmes overseas by a parent institution either operating directly or in association with an international partner. Whilst such programmes have been considered from a pedagogic perspective, their impact on institutional management is under-researched. Yet it is clear that management practice is critical to success or failure. This paper is based on a detailed analysis of institutional audit reports prepared by the Australian Universities Quality Agency (AUQA) in the period 2008-12. The reports are used to identify key issues for institutional management. Building on this analysis, the paper aims to offer a theoretical insight into governance and leadership of transnational programmes and thereby provide practical guidance for strategy formation.
\end{abstract}

\section{Introduction}

Developing transnational education (TNE) programmes is one approach for higher education institutions wishing to develop and diversify their internationalisation strategies, and to help position themselves in new ways within a globalised environment. The delivery of transnational higher education poses a significant challenge to university leadership and governance, including questions of motivation, strategy, risk, funding and human resources, as well as important academic issues, such as the maintenance of standards across a range of locations and/or modes of delivery. The literature on transnational higher education, concerned primarily with the impact of such programmes within particular regions and with matters of pedagogy and quality assurance, has expanded since about 2000 (see, for example, UNESCO-CEPES (2000); McBurnie and Zygoras (2001), Huang (2007) and British Council (2014)). However, the implications for university leadership and governance remain seriously under-researched, especially from an institutional perspective. In response, this paper reports the findings of a research study of the strategic management challenges that universities face in offering TNE programmes as part of their wider internationalisation strategies. The paper uses data drawn from a set of institutional audit reports prepared by the Australian Universities Quality Agency (AUQA) in the period 2008-12. The study aims both to develop theoretical understanding of the integration of governance and leadership in TNE arrangements, and to offer some practical lessons relevant for all university managers and leaders.

\section{Background}

As higher education becomes more globalised, 'internationalisation' has become a key strategy for universities around the world, keen to secure the prestige, status and competitive 'edge' that are perceived to be rewards from internationalization (Altbach and Knight, 2007). Internationalisation embraces many different activities, including recruitment of international students, student and staff mobility, the development of international curricula and international research partnerships, as well as the delivery of programmes in other countries (transnational education). Knight and de Wit 
(1995) outlined four basic approaches to internationalisation: activity, competency, ethos and process. Subsequently, an activity-based conceptualisation has commonly been used (e.g. Marginson and van de Wende, 2007; de Wit, 2010). Knight (2008) favours a process approach, where internationalisation is seen as "a process of integrating an international, intercultural and global dimension into the purpose, functions (teaching, research and service), and delivery of higher education at the institutional and national levels" (Knight, 2008, p xi). All four of Knight's categories are valuable, but the activity and process approaches are the most useful from a management perspective, and were used in this study.

There are various definitions of 'transnational education' (TNE), but, in this paper, TNE refers to the offering overseas of a 'home university' course and award by, or with, overseas partners, or directly through an overseas branch of the university. Such activities may include overseas branch campuses, articulation arrangements and institutional partnerships that provide face-to-face programme delivery.

With the relatively high cost of an overseas education (including fees, accommodation, subsistence, and travel), studying through a TNE partnership has become a popular option for many students. For the universities, TNE helps to diversify their internationalisation strategies; to ensure that students, staff, research, programmes of study and curricula are attuned to the needs of an increasingly globalised economy and workforce; and to generate additional revenue. TNE partnerships also represent one way in which universities can contribute to social and economic development outside their home country.

From a management perspective, all forms of international education pose new challenges to managers, teachers and quality assurance systems in universities (Taylor, 2010a, 2010b). However, offering programmes overseas is a particularly complex undertaking, which poses significant challenges for institutional governance, leadership and management. TNE is widely recognised as a complex and high risk operation. The programmes are developed in one country and delivered in another; teaching is often undertaken by staff of a partner, rather than by staff of the institution awarding the qualification. Local conditions, including methods of delivery and student expectations, and the political context and legislative framework, may be very different from the home country where the institution is based. TNE poses a clear challenge for institutional leaders and managers, with important consequences for both students and staff. However, whilst institutions and quality assurance agencies have paid particular attention to the governance and management of TNE programmes in recent years, empirical research, especially at the "micro" level of individual institutions, remains scarce.

\section{Research approach}

The research involved a thematic analysis of issues about TNE identified by the Australian Universities Quality Agency (AUQA) (2008), in 27 institutional audit reports prepared between 200812. AUQA's concerns were analysed to identify implications for improving governance and management practices relating to TNE in Australian universities. Australian universities, along with British universities, have been pioneers in the field of TNE. Hence, their experience is of interest to university leaders elsewhere with similar goals for expanding their internationalisation strategies. 
The study used thematic analysis (Braun \& Clarke, 2006) to research AUQA's concerns about TNE offerings by Australian universities. The concerns were identified and coded using textual 'triggers' or 'markers' in AUQA's use of words in the Audit Reports. For example, the university 'will need to improve [or monitor]' or should 'remain vigilant about'.

The following are examples of concerns identified in the 27 reports:

University 24, 2010, Extract 4, p32

...A number of high-priority areas include the need to:

Review all existing international partnership agreements to ensure that they are aligned with the University's mission and strategic directions, are of high quality and are financially sustainable and/or have demonstrable strategic value."

University 4, 2009, Extract 2, p35

New TNE programs must undergo the same academic governance scrutiny as all other University programs"

The concerns identified by AUQA were then classified using an analytical framework of six dimensions derived primarily from higher education management theory, AUQA's own review approach (AUQA, 2008) and the authors' own experience in institutional management and the management and review of TNE programmes, as follows:

1. Corporate and academic governance

2. Institutional strategy and leadership

3. Academic practices and activities

4. Student and staff support and resources

5. QA systems

6. Research, research training and community engagement

A total of 204 concerns were identified in the 27 institutional audit reports. This paper is concerned with issues of leadership and governance, so only the first two dimensions are subject to analysis in this paper. Other topics raised by AUQA have, to a certain extent, been discussed in the literature (e.g. Coverdale-Jones, 2012 and Chapman and Pyvis, 2012).

\section{Research results}

The study identified a total of 23 concerns that related to governance, and 96 relating to institutional strategy and leadership. These 119 concerns were grouped into 14 themes (Table 1). The themes were identified by discerning patterns of recurring concerns across institutional reports. The core 
area of concern - the theme identified - was seen as the central aspect within a set of recurring expressions of concern on the same topic.

\begin{tabular}{|c|c|}
\hline \multicolumn{2}{|c|}{ Corporate and academic governance } \\
\hline 1 & $\begin{array}{l}\text { TNE activities were not properly and effectively dealt with within the institution's } \\
\text { governance processes, particularly in relation to the role of Academic Board and the } \\
\text { associated approval pathway and review processes }\end{array}$ \\
\hline 2 & $\begin{array}{l}\text { Campus governance arrangements did not adequately accommodate a) the intermeshing } \\
\text { of campus governance and management with the university's overall structures, and b) the } \\
\text { pressure for campuses to respond effectively to local needs. }\end{array}$ \\
\hline 3 & $\begin{array}{l}\text { There were deficiencies in the processes for ensuring the integrity of the award across all } \\
\text { locations and forms of offering, and, specifically to consistency in the title, content and } \\
\text { format of award testamurs. }\end{array}$ \\
\hline \multicolumn{2}{|c|}{ Institutional Strategy and Leadership } \\
\hline 4 & $\begin{array}{l}\text { TNE initiatives were not sufficiently linked to the university's internationalisation strategy } \\
\text { and overall institutional goals, strategic direction and strategic plans. }\end{array}$ \\
\hline 5 & $\begin{array}{l}\text { Institutional approaches to risk did not encompass the full range of internal and external } \\
\text { risks associated with TNE activities, including academic, financial and reputational risks. }\end{array}$ \\
\hline 6 & $\begin{array}{l}\text { There were inadequate university-level leadership and accountability for TNE strategy and } \\
\text { activities and oversight }\end{array}$ \\
\hline 7 & $\begin{array}{l}\text { There was a lack of systematic processes for selecting partners that utilises a } \\
\text { comprehensive set of criteria describing what the university requires from the partnership } \\
\text { as the basis for the assessment of strategic fit between the prospective partner and the } \\
\text { university. }\end{array}$ \\
\hline 8 & $\begin{array}{l}\text { The specification of responsibilities for programme management, delivery and support in } \\
\text { partnership contracts were unclear and there were inadequate provisions for systematic } \\
\text { review and formal renewal of partnership agreements. }\end{array}$ \\
\hline 9 & $\begin{array}{l}\text { There was a lack of established protocols to ensure an effective, clear, and systematic } \\
\text { approach to university-partner communications, particularly as they relate to university } \\
\text { academic policies, and procedures, administrative processes, and student performance. }\end{array}$ \\
\hline 10 & $\begin{array}{l}\text { Induction and professional development for both 'home' institution and partner staff were } \\
\text { inadequate. }\end{array}$ \\
\hline 11 & $\begin{array}{l}\text { Current staff profiles together with the recruitment processes, workload management, } \\
\text { and continuity and succession planning were insufficient to ensure the ongoing } \\
\text { sustainability of the staffing arrangements for TNE programs. }\end{array}$ \\
\hline 12 & $\begin{array}{l}\text { There was a lack of adequate cost allocation models and expenditure tracking mechanisms } \\
\text { resulting in inaccurate assessments of financial viability. }\end{array}$ \\
\hline 13 & $\begin{array}{l}\text { Institutional approaches to managing the implementation of allocated university-partner } \\
\text { roles and responsibilities were not appropriately systematic or well-articulated. }\end{array}$ \\
\hline 14 & $\begin{array}{l}\text { There were inadequate university controls of the marketing and promotion of TNE } \\
\text { programmes by partners. }\end{array}$ \\
\hline
\end{tabular}

The main theme relating to governance concerned suitable corporate and academic governance structures. The main themes relating to strategy and leadership were the university's rationale for TNE, its place and contribution within the university's internationalisation strategy and overall strategic plan; risk management; and senior-level management responsibilities for the selection and management of partners. 


\section{Analysis}

(i) TNE partnerships and campuses within corporate and academic governance structures

Two major themes suggested that TNE activities were not properly and effectively dealt with within institutional governance processes, particularly in relation to the role of the Academic Board and the associated approval pathway and review processes. A related area of concern was that that campus governance arrangements did not adequately accommodate a) the intermeshing of campus governance and management with the university's overall structures, and b) the pressure for campuses to respond effectively to local needs. The following are examples of concerns raised:

University 15, 2008, Extract 1, p17

Proposals to establish or renew international agreements are considered by the Internationalisation Strategy Committee, not Academic Board's Internationalisation Committee. While this may be appropriate for some international agreements, where there are issues around the comparability of academic standards, Academic Board should have a role in assessing proposals, although in some cases it may be important to ensure simultaneous consideration of academic and financial issues.

University 19, 2008, Extract 3, p30

It appears that Academic Board is not involved in some important aspects of courses taught through educational collaborations, although the Board is the principal academic body responsible for establishing and maintaining the highest standards in teaching and learning and research in the University. [University 19's] rules do not require that courses be approved again if they are being offered at a different location, so matters such as the preparedness of local staff and library resources at educational collaborations are not considered by the Board.

The reports reveal an important tension for leaders and managers to resolve. A key principle in considering TNE programmes is that they need to be the subject of additional approval and review mechanisms reflecting their cross-national dimension, the partnership or branch campus organisational factors and differences in the student and staff profile. However, AUQA was also concerned that standard academic dimensions of TNE programs may not be sufficiently 'mainstreamed' through the academic governance processes such that they are not regarded as an integral part of the university's academic portfolio. Such integration is necessary to ensure that the university does not operate parallel or divergent sets of academic programmes, 'inside' and 'outside' the home country, with different requirements and standards. TNE programmes, in common with all academic programmes of the university, must be approved by the university governing body as part of a formal legal and business process. 
To achieve both the special consideration of TNE matters and their mainstreaming as an integral part of the university's academic programmes, management responsibilities for TNE need to be appropriately allocated, including senior international, business and academic officers of the university. It is also important that the approval and review processes for TNE activities undertaken by both management and the Academic Board incorporate both the special and standard aspects of TNE programmes in a seamless fashion. An effective review and approval process will typically include consideration of the special dimensions of TNE programs by international and business officers, followed by programme approval through normal academic management and governance processes.

Overseas campuses present particular challenges for governance and management. These challenges commonly arise from the greater scale and complexity of branch campus operations, compared with other TNE partnerships, and the need for campuses to respond more directly to local employer, student and government demands. The AUQA reports suggest that universities should develop appropriate governance structures that accommodate the need for formal campus-level reporting and oversight. Clear management structures also need to be developed that complement the governance arrangements as well as accommodating both strategic and local-level management. The level of independence required to deal with local matters is an operational, not a governance matter. Clearly, for a university to maintain its overall institutional integrity and coherent strategy, local matters requiring a strategic response from the university must be referred by local-level management to senior university management. At the same time, the strategic role of a campus, alongside the need for a level of independence, does justify a clear and strong linkage into the governance structures of the Academic Board and Council.

(ii) Strategic purpose, planning and linkage of TNE to university-level strategy

Concerns relating to strategic purpose and planning appear in the reports for almost half the institutions with a total of 16 concerns identified. The main theme is that TNE initiatives were not sufficiently linked with the university's internationalisation strategy and overall institutional goals, strategic direction and strategic plans.

The following quotations illustrate some of the key points emerging:

University 8, 2009, Extract 3, p. 35-6.

The current strategic rationale for targeted selection of TNE partners is not clear and the University has yet to develop a TNE policy. ....the University will need to review the strategic value of all its partnerships to ensure that they are well aligned with University objectives

University 2, 2011, Extract 5, p39

There is a need for the University to give more holistic oversight to its offshore teaching partnerships, to ask itself what these partnerships are doing to assist its vision for internationalization. 
It is apparent that TNE proposals and periodic reviews should examine the role that TNE generally, and specific programmes in particular, have within the university's internationalisation strategy and broader strategic planning. Institutions considering the development of TNE programs should not only look to the potential value and viability of the programme in its own right, but also ensure that the development can be positioned and justified in contributing to the university's internationalisation strategy and broader goals. As a programme proposal is developed, a clear process should be identified for assessing the specific and university-level contributions of the initiative. This should include specific targets with timelines and performance measures. The contributions to the host country should also be considered, including increased access to higher education, improved skill levels and other contributions to the economy and the national interest.

The development of overseas campuses should be considered as a major university-level development, central to the university's development goals, and should not be seen merely as a tangential TNE activity. Overseas campuses can provide a 'hub' for a particular university's TNE and other international activities in the region, so the development of the campus and of the TNE programs in the region should be considered as part of an overall coherent strategy.

(iii) Risk management

This sub-dimension relates to all aspects of risk, including financial, market, academic and reputational risk, and to institutional approaches to risk identification and mitigation.

The reports emphasised that institutional approaches to identifying and managing risk did not encompass the full range of internal and external risks associated with TNE activities. In addition, risk management was fragmented across institutional levels, from programme to university levels, including senior management, Academic Board and Council. Overall, AUQA formed the view that some universities were not sufficiently risk-aware or committed to risk mitigation and that, in some institutions, formal responsibility for risk management was not being effectively exercised.

University 1, 2009, Extract 1, p. 11-12

In general, there seemed to be a disconnection between the strategic risks considered at the Council level and the operational risks considered at a faculty level. In particular, in a review of documentation, the Panel noted that many of the risk analyses conducted for offshore courses failed to include external risks. ... it was not clear to the Panel that [academic risk] is receiving sufficient attention, nor that identified key risks were being followed up with a sense of urgency. ... it will be important that the faculties and the Academic Board assume a greater role and management of identifying and managing academic risks.

University 22, 2009, Extract 2, p31

[University 22] is aware of the significant business and reputational risks in its international operations and has improved its contractual arrangements. ... [and introduced] a rigorous process for monitoring the academic, financial and 
operational performance of its continuing partners.

It was clear from the AUQA reports that risk needs to be considered at all levels of the institution, from operational programme level, to senior management level, and within the governance levels of Academic Board and Council. These considerations need to be articulated to form a coherent process. Following the assessment of risk levels, mitigating strategies need to be devised and implemented to reduce risk to an acceptable level.

However, ' risk management' needs to be distinguished from 'risk avoidance'; the risks associated with transnational education initiatives, as with any new university initiative, need to be assessed strategically. From a strategic management perspective, avoidance of risk is not sufficient justification for withdrawing from or avoiding a venture; all activities have risks which need to be judged against the strategic goals and benefits. Rather than avoid TNE as a particularly 'risky business', Emery and Worton (2014) argue for a comprehensive appraisal of opportunities. They emphasise that every university's internal environment, risk appetite and financial circumstances are different and that institutions should adopt a "risk-based options appraisal approach" to decide, based on their individual circumstances, on their "optimal mode of TNE operation" (p. 4).

(iv) Senior-level management responsibilities for the selection of partners and the form and 'terms' of partnership

AUQA was concerned that there was inadequate university-level leadership and accountability for TNE strategy and activities and oversight. In AUQA's view, apparent in the extracts below, there was a need for specific senior, university-level roles or appointments to ensure proper decision-making, review and accountability. This implied that senior-level oversight will improve the alignment of TNE with the overall strategic purpose and planning of the university.

University 7, 2008, Extract 1, p. 27-28

The Audit Panel heard varying accounts of the responsibilities for international activities overall and for collaborative activities in particular but it is clear that the major responsibility for managing educational collaborations (onshore and offshore) has been given to individual schools or colleges...AUQA expresses concern over a lack of University-wide scrutiny and checks and balances in these arrangements ... [and recommends that the University] consider a dedicated senior executive level appointment to ensure effective leadership and accountability for international activities, particularly for educational collaborations offshore and onshore.

University 26, 2010, Extract 2, p40

...while there are some very strong, and even exemplary, partnerships found, there was a lack of consistency of approach, procedures and processes for TNE programs...

At the strategic and leadership levels, the University should improve central leadership supervision and monitoring of the TNE strategy and activities, including having senior [university] staff available to negotiate TNE agreements. 
The main purpose of introducing a university-level leadership role is to ensure that the university interest prevails over the narrower interests of individual faculties, departments and individuals, and is appropriately linked to university goals and directions. Secondly, a university-level leadership role ensures that decision making proceeds through an explicit formal process that is directly governed by university rules and policies. Any ambiguity in leadership and responsibility across different levels within the university is alleviated. A key focus in allocating university-level responsibilities for TNE among a senior management group should be to ensure clarity of roles with no gaps or overlaps. In establishing new senior level leadership roles for TNE, there are 2 options: 1) to establish a new specific position to focus on international and TNE, or 2) to allocate these responsibilities to existing senior positions, such as the Pro-Vice-Chancellor Academic, the Pro-Vice-Chancellor International and Vice-President Finance, in a coordinated matrix or system.

\section{Discussion}

Using a strategic leadership perspective, the 14 themes were also grouped into three clusters (Figure 1). At the strategic level, these clusters can be seen in the form of an integrated model that provides an overarching structure for examining and improving the governance and leadership of TNE within an institutional framework.

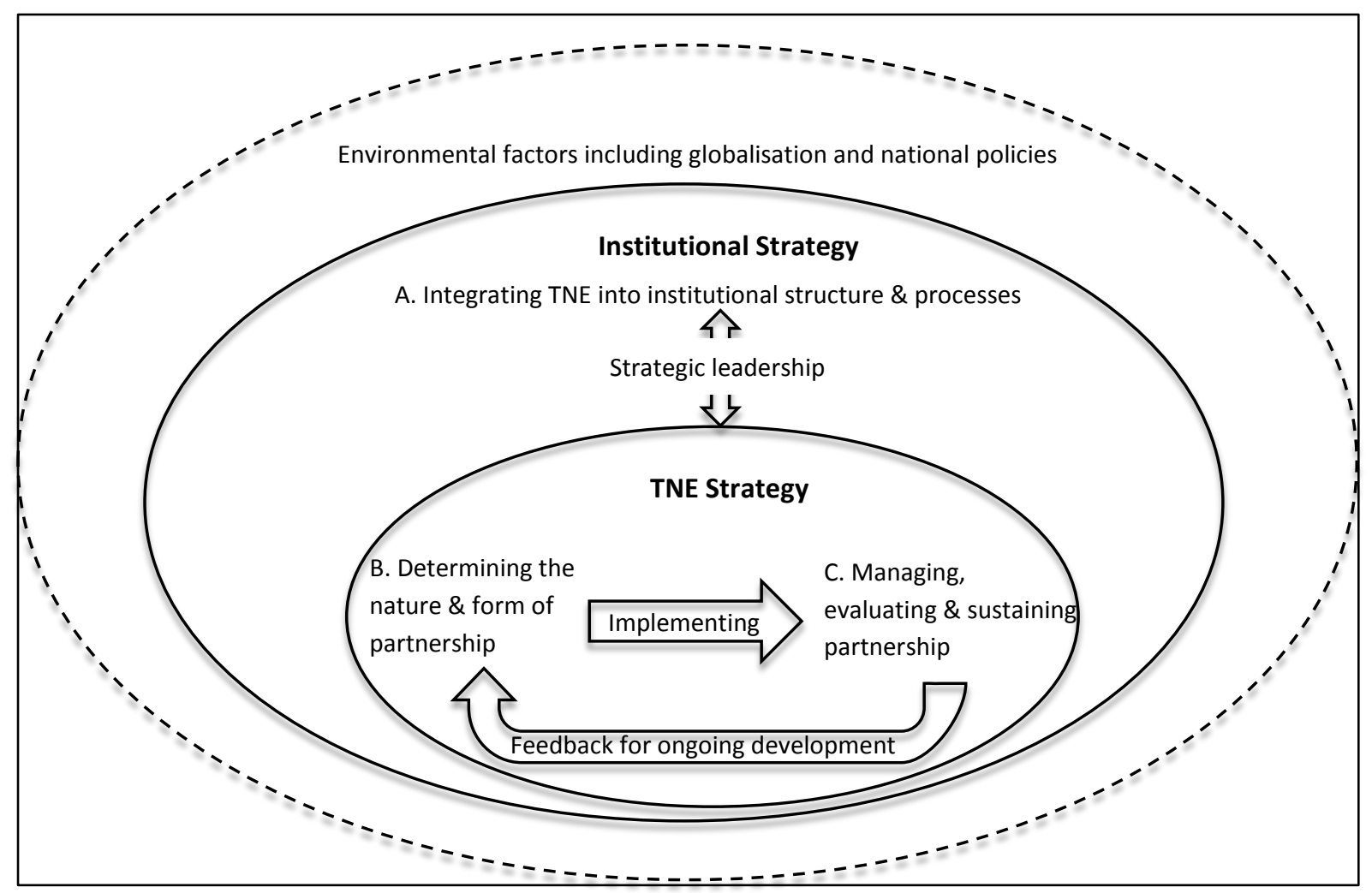


Figure 1. Model of the Strategic-level Integration of Governance and Leadership of TNE Partnerships

Integrating the management of TNE initiatives within institutional governance and management should be a key focus for institutional leaders. An important mechanism in aligning TNE strategy with the institution's international and overall strategies is through strategic leadership. A core strategic task for senior management is to determine the appropriate form of a partnership, with a central consideration being the strategic fit between the prospective partner and the university. Another core strategic task is managing, evaluating and sustaining the partnership so that it makes an ongoing strategic contribution to both the institution and the host country. The central elements of the themes as they relate to the three clusters are shown in Figure 2. 

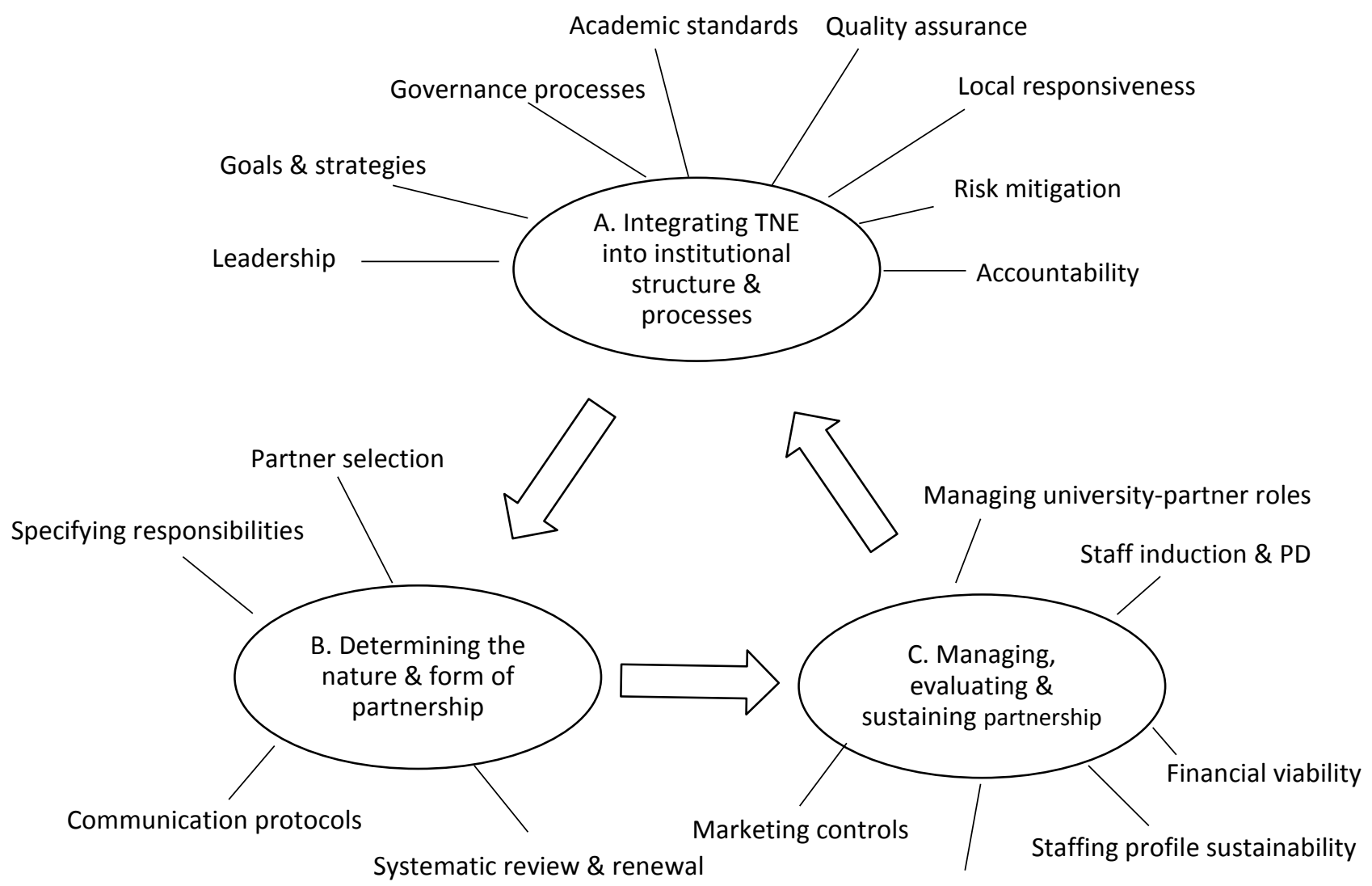

Academic integrity of programmes \& awards

Figure 2. Factors impacting the three summative clusters

\section{Conclusions}

The paper has presented a deeper and more systematic understanding of the nature of TNE and of the issues of governance, strategy and leadership that arise from its inherent complexity and risk. The identification of three strategic clusters and of their inter-relationships has produced original insights into the governance and institutional leadership challenges for the university senior leadership team.

The analysis demonstrates the key roles of the Vice-Chancellor and the senior management team. The changing role of senior management in universities has been widely discussed in the literature, mainly in the context of rapid change and growing environmental complexity (e.g. Middlehurst, 2013). The development of stronger institutional management has been driven by the growing complexity of the environment in which universities operate. The challenges and complexities of internationalising a university are just one of the factors affecting the role of management, but are at the heart of the strategic management issues identified in this paper. 
These changes influence the skills, personal characteristics and experience that are relevant for appointment to a senior role. Drawing upon the specific issues of TNE, but also within the wider context of institutional internationalisation, the Vice-Chancellor needs to have the capacity to:

- think strategically and develop an inspirational and achievable vision

- network effectively across cultures and develop strong reciprocal relationships with carefully selected international partners

- communicate institutional vision and strategy effectively within the institution and with external stakeholders

- be an effective political operator in negotiating through the distributed power structures of universities

- act as a champion for strategic initiatives while at the same time delegating the implementation and operational roles in a coherent and structured way

- evaluate strategically the current effectiveness of an international initiative and its prospects for sustainable development.

The focus on strategic leadership and the role of the Vice-Chancellor in the oversight of TNE brings a parallel need for more sophisciated governance processes capable of responding to increased organisatonal complexity and the particular challenges of operating across national boundaries and cultures. This analysis suggests that governance bodies, too, need the capacity to exercise more strategic and rigorous oversight of senior management within their traditional 'checks and balances' role. In addition, the more complex governance structures and demands that operate transnationally are further complicated by the broader demands that overseas partnerships and branch campuses impose. It is important that governing bodies fully understand their international responsibilities for the development, management and review of international activities.

Although the analysis of governance and leadership concerns in this study was undertaken with data relating to 27 Australian universities, the underlying issues are common in higher education worldwide. All the institutions faced increasing globalisation and the associated pressure to internationalise research, curriculum and staff and student mobility and experience. Further, the strategic tasks of integrating the management of new initiatives into institutional governance and management structures, and aligning new international initiatives with the institution's overall strategies, have general applicability to strategic leadership roles. In relation to both TNE and other international activities, determining the nature and form of a partnership, particularly the strategic fit between the prospective partner and the university, is a key challenge. Finally, all partnerships involve the strategic-level task of managing, evaluating and sustaining the partnership for strategic benefit.

Among the many challenges of operating transnationally, effectively managing the tension between institution-wide integration and local responsiveness (Shams \& Huisman, 2012) requires universities to make a genuine contribution to the host country as well as to the home institution. This tension between goals raises the ethical dimension of international operations. The 'home' and 'host' country economic divide that characterises much TNE and extends to other international ventures raises a clear ethical imperative for Western universities to ensure their international activities are not exploitative (Altbach, 2004). Hence, university leaders must ensure that TNE partnerships are 
both 'symmetrical' and mutually beneficial (Koehn \& Obamba, 2014). In planning and operationalsing their TNE initiatives, institutions should devote particular attention to ensuring the host country and its student population derive substantial benefits from TNE and other international initiatives. Hence, university leaders should focus on transnational partnerships that are genuinely collaborative and sustainable in the long term, and where all partners make progress towards achieving institutional and stakeholder goals.

4998 words

\section{References}

Altbach, P. (2004). Globalisation and the university: Myths and realities in an unequal world. Tertiary Education and Management, 10(1), 3-25. doi: 10.1080/13583883.2004.9967114

Altbach, P., \& Knight J. (2007). The internationalisation of higher education: Motivations and realities. Journal of Studies in International Education, 11(3-4), 290-305.

doi:0.1177/1028315307303542

Australian Universities Quality Agency (AUQA) (2008a). TNE quality framework of AUQA. Available from http://pandora.nla.gov.au/pan/127066/201108260004/www.auqa.edu.au/qualityenhancement/publications/other/index.html

Braun, V., \& Clarke, V. (2006). Using thematic analysis in psychology. Qualitative Research in Psychology, 3(2), 77-101. doi:http://dx.doi.org/10.1191/1478088706qp063oa

Chapman, A., \& Pyvis, D. (2012). Enhancing quality in transnational higher education: Experiences of teaching and learning in Australian offshore programs. Blue Ridge Summit, PA, USA: Lexington Books.

Coverdale-Jones, T. (Ed.). (2012). Transnational higher education in the Asian context. Basingstoke, UK: Palgrave Macmillan.

de Wit, H. (2010). Internationalisation of higher education in Europe and its assessment, trends and issues. The Hague, Netherlands: The Accreditation Organisation of the Netherlands and Flanders (NVAO).

Emery, V., \& Worton, M. (2014). Challenges for the leadership of transnational education in higher education: Balancing risk and innovation. London, UK: Leadership Foundation for Higher Education.

Huang, F. (2007). Developing and Emerging Countries: A Focus on Transnational Higher Education in Asia, Journal of Studies in Higher Education, 11, 421-32 
Koehn, P. H., \& Obamba, M. O. (2014). The transnationally partnered university: Insights from research and sustainable development colalborations in Africa. Retrieved from http://www.palgraveconnect.com/pc/doifinder/10.1057/9781137481757.0001

Knight, J. (2008). Higher education in Turmoil: The changing world of internationalization. Rotterdam, Netherlands: Sense Publishers.

Knight, J., \& de Wit, H. (1995). Strategies for internationalisation of higher education: historical and conceptual perspectives. In H. de Wit (Ed.), Strategies for the internationalisation of higher education. A comparative study of Australia, Canada, Europe and the United States of America (pp 532). Amsterdam, Netherlands: European Association for International Education.

McBurnie, G. \& Ziguras, C. (2001). The regulation of transnational higher education in South East Asia: Case Studies of Hong Kong, Malaysia and Australia, Higher Education, 42, 85-100

McNamara, J. with Knight, J. (2014). Impacts of transnational higher education in host countries, British Council, London.

Marginson, S., \& van de Wende, M. (2007). Globalisation and higher education. (Education Working Paper No. 8). Paris: Organisation for Economic Co-operation and Development (OECD). Retrieved from http://doc.utwente.nl/60264/1/Marginson07globalisation.pdf

Middlehurst, R. (2013). Changing Internal governance: Are leadership roles and management structures in United Kingdom universities fit for the future? Higher Education Quarterly, 67(3), 275294. doi:10.1111/hequ.12018

Shams, F., \& Huisman, J. (2012). Managing offshore branch campuses: An analytical framework for institutional strategies. Journal of Studies in International Education, 16(2), 106-127. doi:10.1177/1028315311413470.

Taylor, J. (2010a). The response of governments and universities to globalization and internationalization in higher education. In F. Maringe \& N. Foskett (Eds.), Globalization and internationalization in higher education (pp. 83-96). London, UK: Continuum International Publishing Group.

Taylor, J. (2010b). The management of internationalization in higher education. In F. Maringe \& N. Foskett (Eds.), Globalization and internationalization in higher education (pp. 97-108). London, UK: Continuum International Publishing Group.

UNESCO-CEPES (2000), Code of good practice in the provision of transnational higher education, Bucharest:Romania 